\title{
In situ measurements and model calculations of primary production in turbid waters
}

\author{
Helgi Arst ${ }^{1, *}$, Tiina Nõges ${ }^{2}$, Peeter Nõges ${ }^{2,3}{ }^{\text {, Birgot Paavel }}{ }^{1}$ \\ ${ }^{1}$ Estonian Marine Institute, University of Tartu, Mäealuse St. 10A, 12618 Tallinn, Estonia \\ ${ }^{2}$ Centre for Limnology, Institute of Agricultural and Environmental Sciences, Estonian University of Life Sciences, \\ 61101 Rannu, Tartumaa, Estonia \\ ${ }^{3}$ European Commission, DG Joint Research Centre, Institute for Environment and Sustainability, TP483, Via E. Fermi, \\ 21020 Ispra (VA), Italy
}

\begin{abstract}
Data on the productivity of aquatic ecosystems helps to understand the food web relationships and functioning of these ecosystems. A semi-empirical model for calculating the phytoplankton primary production in turbid waters was elaborated. In situ measurements of the necessary bio-optical parameters were collected in 3 turbid Estonian lakes from 2003 to 2005. Secchi depth, chlorophyll $a$, and integrated primary production ranged from 0.1 to $3 \mathrm{~m}, 4.2$ to $389 \mathrm{mg} \mathrm{m}^{-3}$, and 17 to $435 \mathrm{mg} \mathrm{C} \mathrm{m}^{-2} \mathrm{~h}^{-1}$, respectively. Two model versions (spectral and integral) were developed for calculating the vertical profiles of primary production, $P(z)$. The basic equation described $P(z)$ as a function of photosynthetically absorbed radiation and quantum yield of carbon fixation. The main difference between the models resides in the data on underwater irradiance. We also derived a new algorithm for calculating the vertical profiles of the quantum yield. According to the statistical parameters the preferable model is the spectral model, but the integral model can also be recommended. The quality of the integral model was increased by changing the coefficients in the quantum yield algorithm, by which we compensated for the errors in photosynthetically absorbed radiation in this model. We conclude that the spectral and integral models perform well in computing primary production in turbid lakes. Both models allowed estimation of the primary production profiles and integrated production of the water column, as well as the daily dynamics and daily and monthly totals.
\end{abstract}

KEY WORDS: Limnology · Marine optics · Bio-optical parameters of lakes · Primary production

\section{INTRODUCTION}

The main aim of productivity measurements in aquatic ecosystems is to better understand the food web relationships and functioning of these ecosystems. Traditional methods of measuring primary production are based on the gas exchange that occurs during the photosynthetic process, and measure either the rate of oxygen release or carbon dioxide uptake by plants. In the latter case, the radioactive ${ }^{14} \mathrm{C}$ method is used. Both methods measure the instantaneous rate of photosynthesis during short ( 1 to $2 \mathrm{~h}$ ) exposures.

Water bodies differ in their ability to bind carbon: the differences can be attributed mainly to differences in productivity. Because of changing light conditions, planktonic photosynthesis has a pronounced daily pattern. In order to acquire integrated results over longer time periods (days, months, years), many consecutive measurements of instantaneous photosynthesis rate should be carried out and integrated. Bio-optical model calculations could provide an alternative to this time-consuming ${ }^{14} \mathrm{C}$ method. Modeling is especially important in turbid waters of high productivity, where the abrupt light gradient may cause large errors if traditional field methods are applied.

Many studies consider photosynthesis and primary production in oceanic waters and clear-water lakes (e.g. Schindler 1978, Fee 1980, Platt 1986, Fee et al. 1987, Platt \& Sathyendranath 1988, Morel \& Berthon 1989, Sathyendranath \& Platt 1989, Sathyendranath 
et al. 1989, Platt et al. 1991, Berthon \& Morel 1992, Kyewalyanga et al. 1992, Sosik 1996, Smith et al. 1998, Siegel et al. 2001). Although many bays, coastal waters, marginal seas and lakes throughout the world are turbid and sometimes highly eutrophic, bio-optical modeling of these waters has attracted less attention than in the open ocean. Relatively few publications concern the coastal zones (Platt \& Jassby 1976, Smith et al. 1989, Kirk 1996, Semovski et al. 1996), marginal seas (Woznyak et al. 1992, 1995), and turbid lakes (Talling et al. 1973, Dekker \& Peters 1993, Kirk 1996, Nõges \& Nõges 1998, Lindell et al. 1999, Arst et al. 2006).

Several studies estimate primary production from light intensity and abundance of phytoplankton pigments (e.g. Bannister 1974, Platt \& Jassby 1976, Morel 1978, Schindler 1978, Tilzer 1984, 1989, Platt 1986, Fee et al. 1987, Platt \& Sathyendranath 1988, Morel \& Berthon 1989, Sathyendranath \& Platt 1989, Sathyendranath et al. 1989, Smith et al. 1989, Schofield et al. 1990, Platt et al. 1991, Berthon \& Morel 1992, Kyewalyanga et al. 1992, Woznyak et al. 1992, 1995, Kirk 1996, Sosik 1996, Siegel et al. 2001), but in some studies the nutrient parameters were also used. Often the water-column-integrated primary production was determined from daily mean averages of photosynthetically active radiation (PAR). Widely used are the methods where the dependence of photosynthesis on available light is expressed by an equation consisting of 2 parameters: (1) the initial slope $\alpha^{\beta}$ [mg C (mg chl a $)^{-1}\left(\text { Einst } \mathrm{m}^{-2}\right)^{-1}$ ] and (2) the assimilation number $P_{m}^{B}\left[\mathrm{mg} \mathrm{C}(\mathrm{mg} \mathrm{chl} \mathrm{a})^{-1} \mathrm{~h}^{-1}\right.$ ] (Platt et al. 1977, Sathyendranath et al. 1989). In these models the data on vertical profiles of PAR (Einst $\mathrm{h}^{-1} \mathrm{~m}^{-2}$ ) are also needed. This is a rather complicated approach and gives results on the basis of radiation integrated over the PAR region. For a reliable description of primary production profiles, however, it is preferable to use a 'spectral approach', in which the model is based on spectral data of underwater quantum irradiance and absorption coefficients of phytoplankton (Platt \& Sathyendranath 1988, Sathyendranath et al. 1989, Smith et al. 1989, Schofield et al. 1990, Kyewalyanga et al. 1992, Kirk 1996, Sosik 1996, Arst et al. 2006).

Our purpose was to elaborate a simple model for estimating the vertical profiles of primary production (as well as their values integrated over the water column) that needs as its initial data a few parameters measured in situ: the vertical profiles of spectral (or integral) underwater quantum irradiance and chlorophyll a (chl a) concentration. In case of the first version (spectral model), we advanced on previous approaches by using both spectral data of underwater quantum irradiance and absorption coefficients of phytoplankton. Our second version (integral model) broadens the applicability of our approach due to the fact that it exploits the easily obtained PAR irradiance data. With these models we are able to reproduce ${ }^{14} \mathrm{C}$ estimates of primary productivity while improving the temporal resolution of productivity.

\section{MATERIALS AND METHODS}

Measurements and study sites. In order to build our models, we obtained numerous in situ primary production profiles and corresponding solar irradiances (incident and underwater), as well as chl a values from 3 shallow, turbid lakes in Estonia. From 2003 to 2005, these measurements were performed repeatedly in 3 Estonian lakes: Lake Peipsi, Lake Võrtsjärv, and Lake Harku. All of these lakes are quite shallow and turbid (Table 1), and similar to other turbid lakes throughout the world (Kirk 1981, Dekker \& Peters 1993, Lindell et al. 1999, Herlevi 2002, Arst 2003). Sampling was conducted on 14 d in Lake Peipsi, on 14 d in Lake Võrtsjärv, and on $8 \mathrm{~d}$ in Lake Harku. Measurements were taken twice daily (about 11:00 to 13:00 and 15:00 to 17:00 h), except when unfavorable weather or logistic problems occurred. Altogether, 53 field and laboratory measurement series were completed in June and August, 2003, and in several months from April to September, 2004 to 2005.

Primary production $P(z)\left(\mathrm{mg} \mathrm{C} \mathrm{m} \mathrm{m}^{-3} \mathrm{~h}^{-1}\right)$ was estimated in situ at 6 different depths in the lake using the ${ }^{14} \mathrm{CO}_{2}$ assimilation technique (Steeman Nielsen 1952) and a $2 \mathrm{~h}$ incubation around midday (the choice of the depths of incubation bottles depended on the transparency of the water). After incubation, the water was acidified $(\mathrm{pH}<2)$ with $0.5 \mathrm{~N} \mathrm{HCl}$ to remove the remaining inorganic ${ }^{14} \mathrm{C}$ (Niemi et al. 1983, Hilmer \& Bate 1989, Lignell 1992), then sample radioactivity was measured in an LSC RackBeta 1211 counter (Wallac) using external standardization for DPM (disintegrations $\min ^{-1}$ ) calculations and Optiphase 'HiSafe 3' scintillation cocktail (Wallac). $P(z)$ was calculated by the

Table 1. Trophic type, main morphometric data, and typical variation of Secchi depth $\left(z_{\mathrm{SD}}\right)$ in the summer of 2003 to 2005 in 3 Estonian lakes (from Arst et al. 2008)

\begin{tabular}{|c|c|c|c|c|c|}
\hline Lake & Trophic type & $\begin{array}{l}\text { Area } \\
\left(\mathrm{km}^{2}\right)\end{array}$ & $\begin{array}{l}\text { Average } \\
\text { depth (m) }\end{array}$ & $\begin{array}{l}\text { Maximum } \\
\text { depth (m) }\end{array}$ & $\begin{array}{l}z_{\mathrm{SD}} \\
(\mathrm{m})\end{array}$ \\
\hline Peipsi & Meso/eutrophic & 2611 & 8.3 & 12.9 & $0.9-3.0$ \\
\hline Võrtsjärv & Eutrophic & 270 & 2.8 & 6.0 & $0.3-1.6$ \\
\hline Harku & Hypertrophic & 1.64 & 2 & 2.5 & $0.1-1.0$ \\
\hline
\end{tabular}


standard formula (Nielsen \& Bresta 1984). Non-photosynthetic carbon fixation was measured in dark vials and subtracted from the light assimilation. Integrated values of primary production, $P_{\text {int }}$, were calculated by integrating $P(z)$ over depth.

Incident planar quantum irradiance $q_{\text {PAR }}(z=0)$ $\left(\mu \mathrm{mol} \mathrm{m} \mathrm{m}^{-2} \mathrm{~s}^{-1}\right)$ was measured above the water every 2 min throughout the $2 \mathrm{~h}$ incubation of the $P(z)$ bottles. For these measurements, we used a LI-192 SA quantum sensor (LI-COR Corporation SA) in the photosynthetically active region (PAR: 400 to $700 \mathrm{~nm}$ ).

Underwater downwelling planar and scalar quantum PAR irradiances, $q_{\text {PAR }}(z)$ (quantum sensor LI-192 $\mathrm{SA}$ ) and $q_{0, \mathrm{PAR}}(z)$ (quantum sensor LI-193 SA), respectively, were determined at several depths $(z)$, giving 2 to 4 vertical profiles of irradiance during each $2 \mathrm{~h}$ period. The choice of depths depended on the transparency of the water. From the profiles of $q_{\text {PAR }}(z)$, we calculated the depth-averaged diffuse attenuation coefficient of PAR, $K_{\mathrm{d}, \mathrm{PAR}}$, using a semi-logarithmic plotting of $q_{\mathrm{PAR}}(z)$ versus depth; $K_{\mathrm{d} \text {,PAR }}$ was equal to the slope of the least-square regression line through these points.

Relative transparency of water was measured by a Secchi disk $\left(Z_{\mathrm{SD}}, \mathrm{m}\right)$ and concentrations of chl a $\left(C_{\mathrm{chl}}\right.$, in

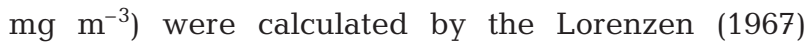
method.

Spectra of the light attenuation coefficient in filtered and unfiltered water samples in the wavelength range of 350 to $700 \mathrm{~nm}$ were obtained using a Hitachi U1000 laboratory spectrophotometer. On the basis of these results, we derived the spectral values of the diffuse attenuation coefficient (Arst et al. 2002, Arst 2003).

The detailed analysis of the results of our in situ and laboratory measurements is presented in Arst et al. (2008). In the present study, we included the minimum and maximum values of crucial parameters for the 3 lakes (Table 2) and vertical profiles of primary production (9 profiles from 53, Figs. 1 \& 2). The 3 lakes differed in bio-optical properties as well as in biological productivity. All 3 lakes were shallow and well-mixed, and showed no substantial variations in vertical profiles of chl a. Thus, we assume the value of $C_{\mathrm{chl}}$ in our calculations to be independent of depth.

Table 2. Minimum and maximum (min-max) chl a contents $\left(C_{\mathrm{chl}}\right)$, diffuse attenuation coefficient $\left(K_{\mathrm{d}, \mathrm{PAR}}\right)$, integrated primary production $\left(P_{\text {int }}\right)$, and the highest value of primary production in its vertical profile $\left(P_{\max }\right)$ in Lakes Peipsi, Võrtsjärv, and Harku from 2003 to 2005 (from Arst et al. 2008)

\begin{tabular}{|lcccc|}
\hline Lake & $\begin{array}{c}C_{\text {chl }} \\
\left(\mathrm{mg} \mathrm{m}^{-3}\right)\end{array}$ & $\begin{array}{c}K_{\mathrm{d}, \mathrm{PAR}} \\
\left(\mathrm{m}^{-1}\right)\end{array}$ & $\begin{array}{c}P_{\text {int }} \\
\left(\mathrm{mg} \mathrm{C} \mathrm{m}^{-2} \mathrm{~h}^{-1}\right)\end{array}$ & $\begin{array}{c}P_{\max } \\
\left(\mathrm{mg} \mathrm{C} \mathrm{m}^{-3} \mathrm{~h}^{-1}\right)\end{array}$ \\
\hline Peipsi & $4.2-37$ & $0.74-2.58$ & $16.6-107$ & $7.8-116$ \\
Võrtsjärv & $28-79$ & $1.65-3.40$ & $42.8-273$ & $23.4-182$ \\
Harku & $54-389$ & $2.50-7.88$ & $39-435$ & $96-1532$ \\
\hline
\end{tabular}

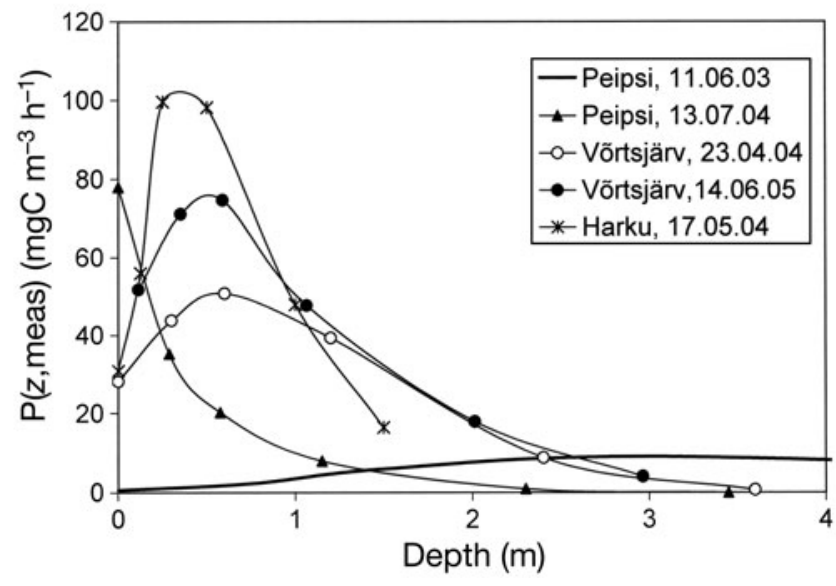

Fig. 1. Vertical profiles of primary production measured in situ $P(z$,meas $)$, from 2003 to 2005: Lake Peipsi at noon on 11 June 2003, where chl a concentration $\left(C_{\text {chl }}\right)=9$, the incident planar quantum irradiance $q_{\mathrm{PAR}}(z=0)=1810$, and the depthaveraged diffuse attenuation coefficient of photosynthetically active radiation $K_{\mathrm{d}, \mathrm{PAR}}=0.74$; Lake Peipsi at noon on 13 July 2004 , where $C_{\text {chl }}=19, q_{\text {PAR }}(z=0)=320$, and $K_{\mathrm{d}, \mathrm{PAR}}=2.6$; Lake Võrtsjärv at noon on 23 April 2004, where $C_{\text {chl }}=28, q_{\text {PAR }}(z=0)$ $=1030$, and $K_{\mathrm{d}, \mathrm{PAR}}=1.6$; Lake Võrtsjärv on the afternoon of 14 June 2005, where $C_{\text {chl }}=42, q_{\mathrm{PAR}}(z=0)=1000$, and $K_{\mathrm{d}, \mathrm{PAR}}=$ 2.2; Lake Harku on the afternoon of 17 May 2004, where $C_{\text {chl }}=62, q_{\mathrm{PAR}}(z=0)=1000$, and $K_{\mathrm{d}, \mathrm{PAR}}=2.7$. The parameters

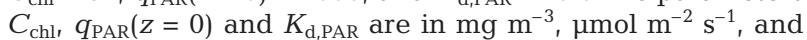
$\mathrm{m}^{-1}$, respectively

Typical profiles of $P(z)$ from the lakes usually showed a minimum at the water surface due to inhibition, then an increase to a maximum at some depth, followed by decreasing production at depth (Figs. 1 \& $2)$. There can be some exceptions, however: in low illumination, the maximum of the $P(z)$ curve is located at or near the surface [Fig. 1 for Lake Peipsi (13 July 2004), when $q_{\mathrm{PAR}}(z=0)$ was only $320 \mu \mathrm{mol} \mathrm{m} \mathrm{m}^{-2} \mathrm{~s}^{-1}$ ]. Consequently, the algorithms of any primary production model should give the results that correspond to 'normal' shapes of $P(z)$ profiles.

Basic equations of the model. Our purpose was to compile a primary production model that applies the spectral values of underwater quantum irradiance and chl a concentration as initial parameters. The general approach was similar to that of Smith et al. (1989), where $P(z)$ was described by the following simple equation:

$$
P(z)=\Psi Q_{\mathrm{PAR}}(z) F_{\mathrm{PAR}}(z)
$$

where $P(z)$ is in milligrams of carbon per cubic meter per hour, $\Psi$ is the factor 12000 for converting moles of carbon to milligrams of carbon, $Q_{\mathrm{PAR}}(z)$ is the photosynthetically absorbed radia- 


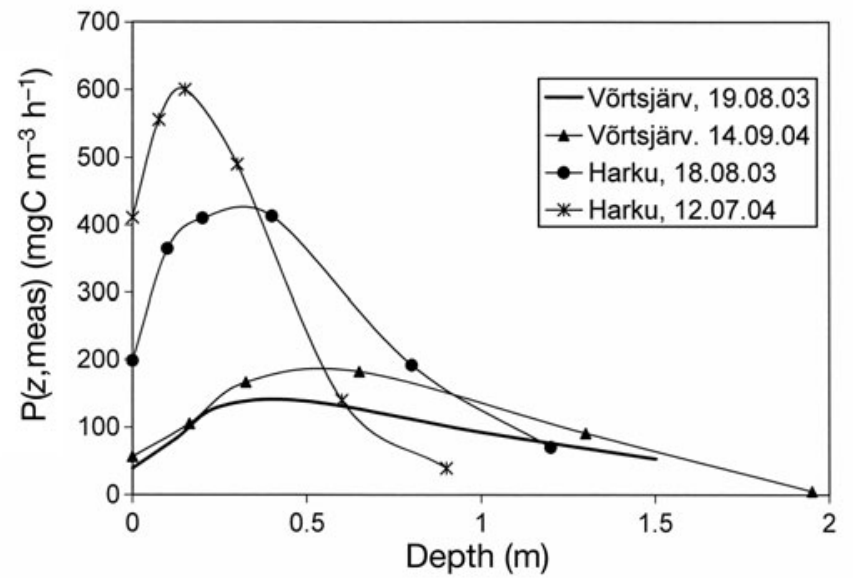

Fig. 2. Vertical profiles of primary production measured in situ $P(z$, meas $)$, from 2003 to 2005: Lake Võrtsjärv at noon on 19 August 2003, where $C_{\mathrm{chl}}=59, q_{\mathrm{PAR}}(z=0)=1700$, and $K_{\mathrm{d}, \mathrm{PAR}}=3$; Lake Võrtsjärv on the afternoon of 14 September 2004 , where $C_{\text {chl }}=79, q_{\mathrm{PAR}}(z=0)=1300$, and $K_{\mathrm{d}, \mathrm{PAR}}=2.5$; Lake Harku at noon on 18 August 2003, where $C_{\mathrm{chl}}=107$, $q_{\mathrm{PAR}}(z=0)=1800$, and $K_{\mathrm{d}, \mathrm{PAR}}=4$; Lake Harku at noon on 12 July 2004, where $C_{\text {chl }}=146, q_{\text {PAR }}(z=0)=1310$, and $K_{\text {d,PAR }}$ $=6$; The parameters $C_{\mathrm{chl}}, q_{\mathrm{PAR}}(z=0)$, and $K_{\mathrm{d}, \mathrm{PAR}}$ (and the units used) are defined in Fig. 1

tion at depth $z$ (in Einst $\mathrm{m}^{-3} \mathrm{~h}^{-1}$ ) and $F_{\mathrm{PAR}}(z)$ is the quantum yield of carbon fixation $\left(\mathrm{mol} \mathrm{C} \mathrm{Einst}{ }^{-1}\right)$ in the range of 400 to $700 \mathrm{~nm}$.

The value of $Q_{\mathrm{PAR}}(z)$ depends on the pigmentspecific absorption coefficients and the concentration of each pigment in the phytoplankton (Smith et al. 1989); however, often, such detailed data are not available. We used the simplified equation:

$$
Q_{\mathrm{PAR}}(z)=\int_{400}^{700} q(\lambda, z) a_{\mathrm{ph}}^{\prime}(\lambda) C_{\mathrm{chl}} \mathrm{d} \lambda
$$

Here, $q(\lambda, z)$ is the spectral quantum irradiance at wavelength $\lambda$ and depth $z$ (Einst $\left.\mathrm{m}^{-2} \mathrm{~nm}^{-1} \mathrm{~h}^{-1}\right), C_{\mathrm{chl}}$ is the concentration of $\operatorname{chl} a$, and $a_{\mathrm{ph}}^{\prime}(\lambda)$ is the specific absorption coefficient of phytoplankton, obtained as an average for some typical species combinations.

It should be noted that using averaged spectra of $a^{\prime}{ }_{p h}(\lambda)$ brings about some unreliability in the values of $Q_{\mathrm{PAR}}(z)$, due to variability of the phytoplankton pigments (as well as their spectra) from lake to lake and also with season. However, it is not rational to create series of primary production models for each individual case, taking into account the specificity of phytoplankton spectra. Thus, we decided to use some generalized spectra of $a^{\prime}{ }_{p h}(\lambda)$, hoping that after all we could obtain a sufficient model for computing phytoplankton production profiles in the water.

We used an algorithm presented by Bricaud et al. (1995):

$$
a_{\mathrm{ph}}^{\prime}(\lambda)=A(\lambda) C_{\mathrm{chl}}^{-B(\lambda)}
$$

where the specific absorption coefficient $a_{\mathrm{ph}}^{\prime}(\lambda)$ is calculated taking into account the 'package effect' (Morel \& Bricaud 1981, Bricaud et al. 1995, Kirk 1996). $A$ and $B$ are positive, wavelength-dependent parameters, as tabulated in Bricaud et al. (1995). Their study used 815 spectra of living phytoplankton in different regions of the world ocean and covered a $C_{\mathrm{chl}}$ range from 0.25 to $25 \mathrm{mg} \mathrm{m}^{-3}$. Although widely used, the parameters $A$ and $B$ in Bricaud et al. (1995) may not be reliable for eutrophic lake waters with high $C_{\text {chl }}$. However, we could not find any publications with the spectra of $A$ and $B$ for very turbid lakes. Thus, we used Bricaud's data and hoped that, through the process of quantifying, we could elaborate a proper model for estimating of phytoplankton production profiles in lakes.

The values of $q(\lambda, z)$ can be determined from either underwater measurements using a spectrophotometer, or corresponding values of $q(\lambda, z=0)$ and the spectral diffuse attenuation coefficient $K_{\mathrm{d}}(\lambda)$. Although $K_{\mathrm{d}}(\lambda)$ can also depend on depth, the 3 lakes sampled were not stratified, and we used the following formula (Dera 1992, Kirk 1996, Arst 2003):

$$
q(\lambda, z)=(1-r) q(\lambda, z=0) \exp \left[-K_{\mathrm{d}}(\lambda) z\right]
$$

where $r$ is the mean value solar radiation $(r \approx 0.06)$ reflected from water surface.

Determination of $Q_{\mathrm{PAR}}(z)$ from Eqs. (2) to (4) provides a spectral model for computing $P(z)$.

When spectral data are lacking, a primary production model can be built using integral values of incident irradiance and underwater irradiance, averaged over PAR waveband absorption coefficients of phytoplankton, $a_{\text {ph,PAR }}$ as follows:

$$
\begin{gathered}
Q_{\mathrm{PAR}}(z) \approx q_{\mathrm{PAR}}(z) a_{\mathrm{ph}, \mathrm{PAR}} \\
q_{\mathrm{PAR}}(z)=\int_{400}^{700} q(\lambda, z) \mathrm{d} \lambda \\
a_{\mathrm{ph}, \mathrm{PAR}}=\frac{\int_{400}^{700} a_{\mathrm{ph}}^{\prime} C_{\mathrm{chl}}(\lambda) \mathrm{d} \lambda}{\int_{400}^{700} \mathrm{~d} \lambda}
\end{gathered}
$$

Note that although Eq. (4) describes the attenuation of spectral irradiance, a similar exponential law is also widely used to calculate the values of integral underwater irradiance, $q_{\mathrm{PAR}}(z)$ :

$$
q_{\mathrm{PAR}}(z)=q_{\mathrm{PAR}}(z=-0) \exp \left(-K_{\mathrm{d}, \mathrm{PAR}} z\right)
$$

where $q_{\mathrm{PAR}}(z=-0)=(1-r) q_{\mathrm{PAR}}(z=0)$. The reliability of this approach for ice-free water bodies was estimated in Arst et al. (2000).

Eqs. (5) to (8) together with Eq. (1) are the basic equations of an integral (or broad-band) model. 
Because the algal cells are illuminated from all directions, primary production calculations should be performed using scalar quantum irradiance $\left[q_{0}(\lambda, z)\right.$ and $\left.q_{0, \mathrm{PAR}}(z)\right]$ data, not underwater planar quantum irradiance $\left[q(\lambda, z)\right.$ or $\left.q_{\mathrm{PAR}}(z)\right]$ (Kirk 1996, Sosik 1996); therefore, in the spectral model, the photosynthetically absorbed radiation [using a new denotation, $Q_{\mathrm{PAR}}^{*}(z)$ ] should be computed by the following equation:

$$
Q_{\mathrm{PAR}}^{*}(z)=\int_{400}^{700} q_{0}(\lambda, z) a_{\mathrm{ph}}^{\prime}(\lambda) C_{\mathrm{chl}} \mathrm{d} \lambda
$$

In the integral model, $Q_{\mathrm{PAR}}^{*}(z)$ should be computed by the following equation:

$$
Q_{\mathrm{PAR}}^{*}(z)=q_{0, \mathrm{PAR}}(z) a_{\mathrm{ph}, \mathrm{PAR}}(z)
$$

Consequently, instead of Eq. (1), we now have the following equation:

$$
P(z)=\Psi Q_{\mathrm{PAR}}^{*}(z) F_{\mathrm{PAR}}(z)
$$

In this equation, $Q_{\mathrm{PAR}}^{*}(z)$ is determined from scalar quantum irradiance.

\section{RESULTS AND DISCUSSION}

\section{Correction for derivation of $Q_{\mathrm{PAR}}^{*}(z)$ from the values of $Q_{\text {PAR }}(z)$}

We had no spectral data on $q_{0}(\lambda, z)$; consequently, we could not determine $Q_{\mathrm{PAR}}^{*}(z)$ directly using Eq. (9). We hypothesized that $Q_{\mathrm{PAR}}^{*}(z)$ can be estimated from $Q_{\text {PAR }}(z)$ using a correction, $C(z)$ as follows:

$$
Q_{\mathrm{PAR}}^{*}(z) \approx C(z) Q_{\mathrm{PAR}}(z)
$$

where $Q_{\text {PAR }}(z)$ should be calculated by Eq. (2). We assumed that this correction could be estimated from measured in situ planar and scalar quantum irradiances, specifically:

$$
C(z)=\frac{q_{0, \mathrm{PAR}}(z)}{q_{\mathrm{PAR}}(z)}
$$

The relationship $\frac{q_{0, \mathrm{PAR}}(z)}{q_{\mathrm{PAR}}(z)}$ is known to depend on the angular structure of the underwater light field, on the incident solar irradiance, on the solar zenith angle, and on the absorption and scattering properties of the aquatic environment. In the upper layer of an ice-free water body, the ratio $q_{0, \mathrm{PAR}} / q_{\mathrm{PAR}}$ generally increases with depth, with the numerical values usually remaining between 1.1 and 2.5 (Reinart 2000). In clear-water lakes at deeper layers, the asymptotic state of the angular structure of light is reached, but that was not observed in the shallow turbid Estonian lakes. The ratio $q_{0, \mathrm{PAR}} / q_{\mathrm{PAR}}$ we measured near the surface was between 1.3 and 1.8, increasing with increasing turbidity of the water. This ratio reached about 1.7 at $5 \mathrm{~m}$ depth in Lake Peipsi, about 2.2 at $2.5 \mathrm{~m}$ in Lake Vorrtsjärv, and about 3.5 at $1 \mathrm{~m}$ in Lake Harku. These values of $q_{0, \mathrm{PAR}} / q_{\mathrm{PAR}}$ show that the use of planar irradiance without a correction coefficient instead of scalar irradiance should be avoided in bio-optical models.

For our model, we needed a generalized algorithm of $C(z)$ that allowed calculation of values for each depth. We assumed that $C(z)$ is a function of $C_{\mathrm{chl}}$ and the diffuse attenuation coefficient of light, $K_{\mathrm{d}, \mathrm{PAR}}$. We performed a regression analysis on measured in situ $C_{\mathrm{chl}}$, $K_{\mathrm{d}, \mathrm{PAR}}$, and the respective $q_{\mathrm{PAR}}(z)$ and $q_{0, \mathrm{PAR}}(z)$ values, and found that the best regression curve for the parameter $C(z)$ was an exponent. We found that rather good results can be obtained when we suppose that the first coefficient of this exponent depends only on $K_{\mathrm{d}, \mathrm{PAR}}$, and the second coefficient, only on $C_{\text {chl }}$. The regression analysis gave the following results:

$$
\begin{gathered}
C\left(z, C_{\mathrm{chl}}, K_{\mathrm{d}, \mathrm{PAR}}\right)=C_{1} \exp \left(C_{2} z\right) \\
C_{1}=1.32 K_{\mathrm{d}, \mathrm{PAR} i}^{0.153} \mathrm{R}^{2}=0.692, \mathrm{p}<0.0001 \\
C_{2}=0.0023 C_{\mathrm{chl}}+0.016 ; \mathrm{R}^{2}=0.819, \mathrm{p}<0.0001
\end{gathered}
$$

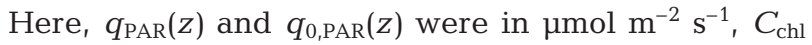
was in $\mathrm{mg} \mathrm{m}^{-3}$ and $K_{\mathrm{d}, \mathrm{PAR}}$ was in $\mathrm{m}^{-1}$.

The reliability of Eqs. (14) to (16) needs confirmation. For this we compared measured and calculated $q_{0, \mathrm{PAR}}(z)$. We computed 107 vertical profiles (1651 individual measurements) of $q_{0, \mathrm{PAR}}(z)$ from Eqs. (13) to (16), using respective $q_{\mathrm{PAR}}(z), C_{\mathrm{chl}}$, and $K_{\mathrm{d}, \mathrm{PAR}}$, which all were measured in situ. We excluded data from depths of $<10 \mathrm{~cm}$ because undulation of the spherical sensor made readings unreliable. The following regression formula was obtained:

$$
q_{0, \mathrm{PAR}}(\text { meas, } z)=-0.23+1.002 q_{\mathrm{PAR}}\left(\operatorname{call}_{1}, z\right)
$$

where $\mathrm{N}=1651, \mathrm{R}^{2}=0.984, \mathrm{SE}=43 \mu \mathrm{mol} \mathrm{m} \mathrm{m}^{-2} \mathrm{~s}^{-1}, \mathrm{p}<$ 0.000001 , and mean absolute error and mean absolute relative error were $0.4 \mu \mathrm{mol} \mathrm{m} \mathrm{m}^{-2} \mathrm{~s}^{-1}$ and $12.6 \%$, respectively (Fig. 3). These estimates show that Eqs. (14) to (16) provide reliable values of $q_{0, \text { PAR }}(z)$.

Consequently, we first must determine $Q_{\mathrm{PAR}}(z)$ from the spectral or integral method, and then use Eqs. (12) to (16) to calculate the respective $Q_{\mathrm{PAR}}^{*}(z)$.

\section{Algorithm to determine the quantum yield}

Our purpose was to derive an algorithm of quantum yield that was based on the same initial data as the algorithm for photosynthetically absorbed radiation. Smith et al. (1989) proposed the following equation:

$$
F(z)=\frac{F_{\text {max }} k_{\mathrm{F}}}{k_{\mathrm{F}}+q_{\mathrm{PAR}}(z)}
$$




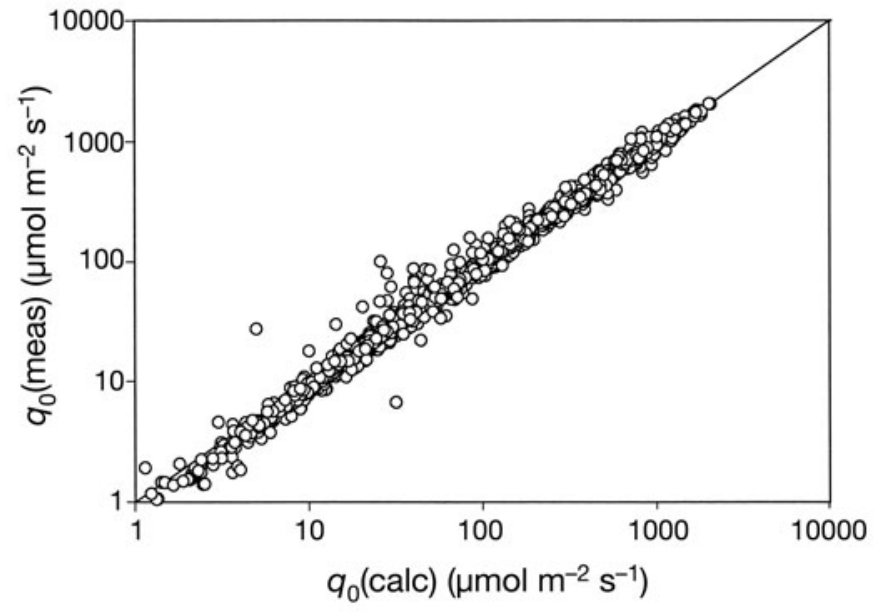

Fig. 3. Regression of underwater downwelling scalar quantum PAR irradiances $q_{0, \mathrm{PAR}}$ (measured, $z$ ) versus $q_{0, \mathrm{PAR}}$ (calculated, z) (Eqs. 13 to 16), in 3 Estonian lakes from 2003 to $2005, N=1651$

where $F_{\max }$ and $k_{\mathrm{F}}$ were treated as the constants, $F_{\max }=$ $0.08 \mathrm{~mol} \mathrm{C}$ Einst $^{-1}$ and $k_{\mathrm{F}}=10$ Einst $\mathrm{m}^{-2} \mathrm{~d}^{-1}$. Taking into account Eq. (8) we arrive at the following equation:

$$
F(z)=\frac{F_{\text {max }} k_{\mathrm{F}}}{k_{\mathrm{F}}+q_{\mathrm{PAR}}(z=-0) \exp \left(-K_{\mathrm{d}, \mathrm{PAR}} z\right)}
$$

Because our in situ data were per hour, and we could not use $k_{\mathrm{F}}$ in Einst $\mathrm{m}^{2} \mathrm{~d}^{-1}$, we performed a mathematical analysis in order to estimate the suitability of Eq. (18). The integral model of primary production was most straightforward, according to Eqs. (1), (5), (8), and (19), as follows:

$$
\begin{aligned}
& P(z)=\Psi Q_{\mathrm{PAR}}(z) F(z)= \\
& \Psi a_{\mathrm{ph}, \mathrm{PAR}} F_{\mathrm{max}} k_{\mathrm{F}} \frac{q_{\mathrm{PAR}}(z=-0) \exp \left(-K_{\mathrm{d}, \mathrm{PAR}} z\right)}{k_{\mathrm{F}}+q_{\mathrm{PAR}}(z=-0) \exp \left(-K_{\mathrm{d}, \mathrm{PAR}} z\right)}
\end{aligned}
$$

The parameters $\Psi, a_{\text {ph,PAR }}, q_{\mathrm{PAR}}(z=-0), F_{\text {max }}$, and $k_{\mathrm{F}}$ do not depend on depth, and their product can be considered to be a constant $(H)$. Thus, Eq. (20) becomes:

$$
P(z)=H \frac{1}{k_{\mathrm{F}} \exp \left(K_{\mathrm{d}, \mathrm{PAR}} z\right)+q_{\mathrm{PAR}}(z=-0)}
$$

Because $\Psi, a_{\text {ph,PAR }}, q_{\text {PAR }}(z=-0), F_{\text {max }}, k_{\mathrm{F}}$, and $K_{\mathrm{d}, \mathrm{PAR}}$ are positive values, the vertical profile of primary production, as determined by Eq. (21), always shows decreasing of $P(z)$ with increasing depth. Consequently, when using Eq. (18) (from Smith et al. 1989), we can never obtain the typical profiles of $P(z)$ with a maximum at some depth (like the measured profiles in Figs. 1 \& 2).

Thus, we needed a new algorithm for computation of quantum yield. We tested (by using a fitting method) different modifications of Eq. (18). Our purpose was to find an algorithm for $F_{\mathrm{PAR}}(z)$ that is capable of giving shapes of primary production profiles similar to those measured in situ. The best results gave the following modification:

$$
F_{\mathrm{PAR}}(z)=\frac{F_{\text {max }}}{\left[1+M q_{\mathrm{PAR}}(z)\right]^{n}}
$$

where $F_{\text {max }}=0.08 \mathrm{~mol} \mathrm{C}$ Einst $^{-1}$ and $M$ and $n$ are the parameters that can depend on incident irradiance as well as on the bio-optical characteristics of the water body. Some examples of testing the ability of Eq. (22) to give the typically observed shapes of primary production profiles are shown in Fig. 4, the corresponding vertical profiles of quantum yield are in Fig. 5. In these calculations we used some realistic values of $q_{\text {PAR }}(z=0)$ (Einst $\left.\mathrm{m}^{-2} \mathrm{~h}^{-1}\right), K_{\mathrm{d}, \mathrm{PAR}}\left(\mathrm{m}^{-1}\right)$, and $C_{\mathrm{chl}}\left(\mathrm{mg} \mathrm{m}^{-3}\right)$, and the parameters $M$ and $n$ were taken provisionally to be constants. Because the unit $\mu \mathrm{mol}$

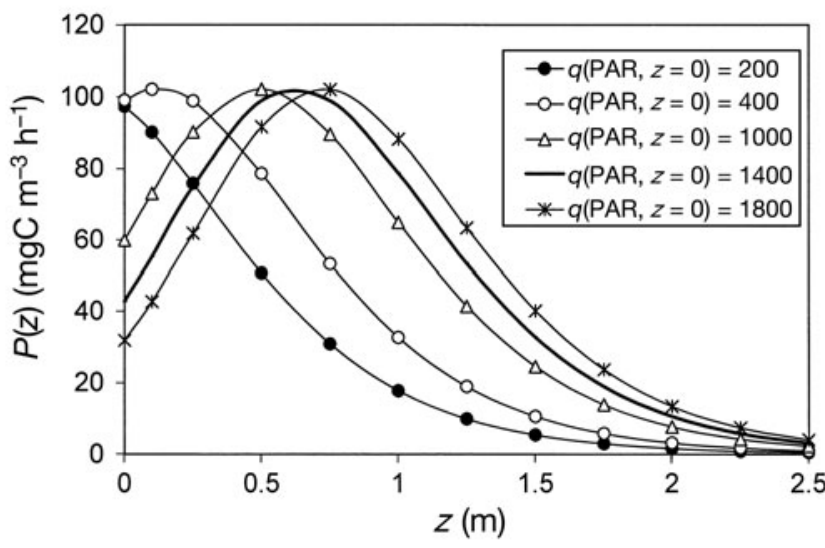

Fig. 4. Changes in the depths of the maximum primary production, $P(z)$, with variation of incident irradiance. The computations are made by Eqs. (1), (5), (7), and (22), taking $C_{\text {chl }}=50 \mathrm{mg} \mathrm{m}^{-3}, K_{\mathrm{d}, \mathrm{PAR}}=2.5 \mathrm{~m}^{-1}, M=0.5$, and $n=3$. The parameters $C_{\text {chl }}, q_{\text {PAR }}(z=0)$, and $K_{\mathrm{d}, \mathrm{PAR}}$ are defined in Fig. 1

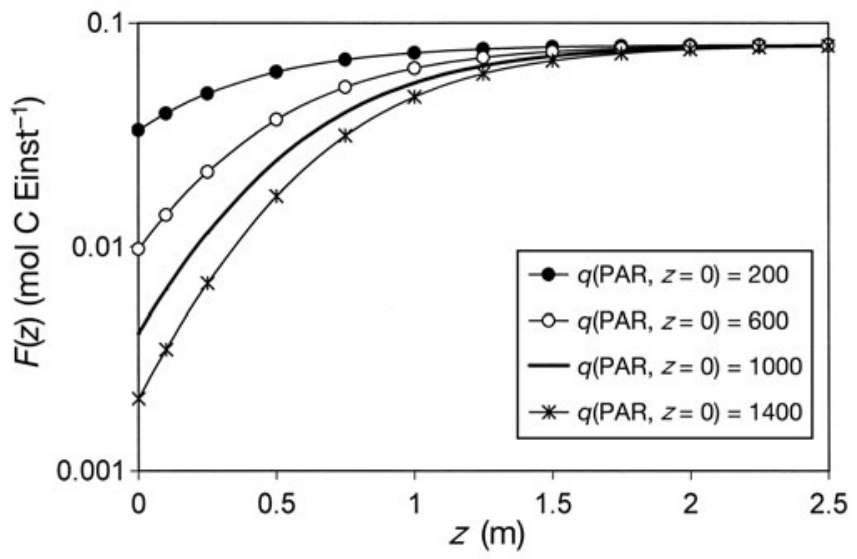

Fig. 5. Vertical profiles of quantum yield $F(z)$, corresponding to the results of Fig. 4 (i.e. the values of $q_{\mathrm{PAR}}(z=0), C_{\mathrm{chl}}$ and $K_{\mathrm{d}, \mathrm{PAR}}$ are the same) 
$\mathrm{m}^{-2} \mathrm{~s}^{-1}$ is more commonly used than as Einst $\mathrm{m}^{-2} \mathrm{~h}^{-1}$, in these figures $q_{\text {PAR }}(z=0)$ is given in $\mu \mathrm{mol} \mathrm{m} \mathrm{m}^{-2} \mathrm{~s}^{-1}$.

Only in the case of low illumination is the maximum of primary production $\left(P_{\max }\right)$ located at the surface; e.g. $q_{\mathrm{PAR}}(z=0)=200 \mu \mathrm{mol} \mathrm{m} \mathrm{m}^{-2} \mathrm{~s}^{-1}$ in Fig. 4. As $q_{\mathrm{PAR}}(z=0)$ increases, $P_{\max }$ moves towards greater depths.

In order to determine which way the coefficients $n$ and $M$ (Eq. 22) influenced the vertical profile of primary production, we calculated $P(z)$ for different $n$ and $M$, taking $q_{\mathrm{PAR}}(z=0)=1400 \mu \mathrm{mol} \mathrm{m}{ }^{-2} \mathrm{~s}^{-1}, C_{\mathrm{chl}}=50 \mathrm{mg}$ $\mathrm{m}^{-3}$, and $K_{\mathrm{d}, \mathrm{PAR}}=2.5 \mathrm{~m}^{-1}$. The $P(z)$ profile depended on the variations of $n$ and/or $M$ until some depth, but there was almost no influence of $n$ and $M$ in deeper layers (Fig. 6).

\section{Quantification of a primary production model}

Determination of $q(\lambda, z)$ and $Q_{\mathrm{PAR}}^{*}(z)$ from in situ data

As shown, determination of $Q_{\mathrm{PAR}}(z)$ requires the values of $q(\lambda, z)$ or corresponding $q(\lambda$, incident $)$ and $K_{\mathrm{d}}(\lambda, z)$ (Eqs. $2 \& 4)$, which can be provided with an underwater spectrophotometer. We had only the spectra of the beam attenuation coefficient $C(\lambda)$, measured from water samples using the laboratory spectrophotometer U1000 (Hitachi). Thus, we had to calculate the values of $q(\lambda, z)$ indirectly. In order to accomplish this, first, during the $2 \mathrm{~h}$ incubation period of $P(z)$, we recorded the incident $q_{\text {PAR }}$ using the PAR waveband sensor LI-192 SA, and computed its hourly average value. Then, by use of a model for spectral distribution of downwelling solar irradiance by Bird \& Riordan (1986) $\left(E_{\mathrm{d}}\right.$, in $\left.\mathrm{W} \mathrm{m}^{-2}\right)$, we found the contributions, $W(\Delta \lambda)$, of

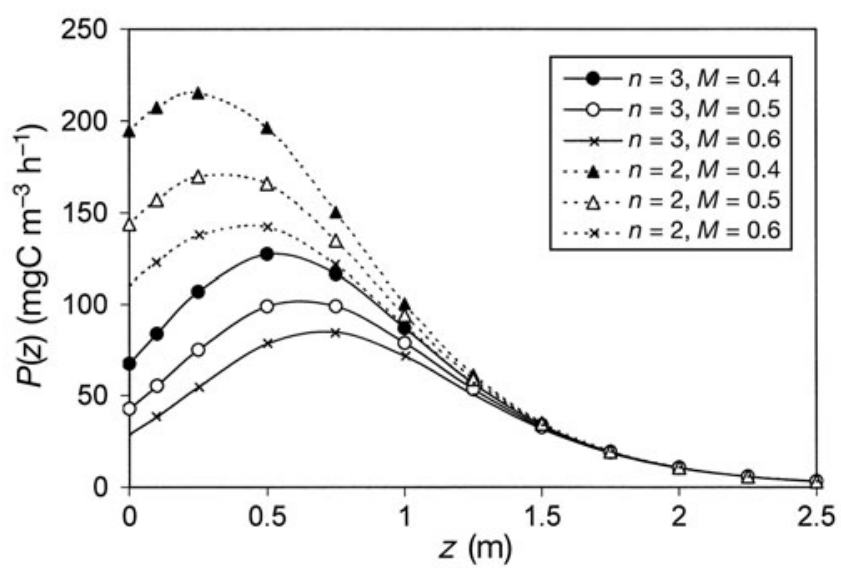

Fig. 6. Variation in primary production, $P(z)$, with changes of $n$ and $M$ in Eq. (22). The computations were made using Eqs. (1), (5), (7), and (22), taking $q_{\mathrm{PAR}}(z=0)=1400 \mu \mathrm{mol} \mathrm{m} \mathrm{m}^{-2}$ $\mathrm{s}^{-1}, C_{\mathrm{chl}}=50 \mathrm{mg} \mathrm{m}^{-3}$, and $K_{\mathrm{d}, \mathrm{PAR}}=2.5 \mathrm{~m}^{-1}$. The parameters $C_{\text {chl }}, q_{\text {PAR }}(z=0)$, and $K_{\mathrm{d}, \mathrm{PAR}}$ are defined in Fig. 1 narrow $(10 \mathrm{~nm})$ wavebands in the PAR region for a given solar zenith angle. After, we converted these results into Einst $\mathrm{m}^{-2} \mathrm{~h}^{-1}$ (Dera 1992, Arst 2003), we could compute the necessary values of $q(\Delta \lambda, z=0)$. For determination of the spectral diffuse attenuation coefficients $K_{\mathrm{d}}(\Delta \lambda)$ for intervals $\Delta \lambda$, we used the spectra of $C(\Delta \lambda)$, measured from corresponding water samples in the laboratory, and the model described in Arst et al. (1997, 2002) and Arst (2003).

The vertical profiles of downwelling planar quantum irradiance were calculated as follows:

$q(\Delta \lambda, z)=W(\Delta \lambda)(1-r) q_{\mathrm{PAR}}(z=0) \exp \left[-K_{\mathrm{d}}(\Delta \lambda) z\right]$

where $W(\Delta \lambda)$ is a weighting coefficient (the contribution of each narrow interval in the PAR quantum irradiance), $r=0.06, K_{\mathrm{d}}(\Delta \lambda)$ is the diffuse attenuation coefficient of light in the interval $\Delta \lambda$, and $q_{\text {PAR }}(z=0)$ is the incident radiation on the water surface averaged hourly during the incubation period of the $P(z)$ bottles. Then, $q_{\text {PAR }}(z)$ is the sum over the waveband 400 to $700 \mathrm{~nm}$, as in the following equation:

$$
q_{\mathrm{PAR}}(z)=\sum_{\Delta \lambda} q(\Delta \lambda, z) \Delta \lambda
$$

We estimated the depth-averaged diffuse attenuation coefficient, $K_{\mathrm{d} \text { PAR }}$ from vertical profiles of $q_{\text {PAR }}(z)$ calculated using Eq. (24). Similarly, we were able to determine $K_{\mathrm{d}, \mathrm{PAR}}$ from our measured in situ $q_{\mathrm{PAR}}(z)$ profiles. Thus, we could compare the model values of $K_{\mathrm{d}, \mathrm{PAR}}$ with those obtained from in situ measurements.

We can estimate the relative differences (RE) between $q_{\text {PAR }}(z)$ values comparing the results by integral and spectral models, $q_{\text {PAR }}(\mathrm{int})$ and $q_{\text {PAR }}(\mathrm{sp})$, respectively, from the following formula:

$$
\mathrm{RE}=\frac{2\left[q_{\mathrm{PAR}}(\text { int })-q_{\mathrm{PAR}}(s p)\right]}{\left[q_{\mathrm{PAR}}(\mathrm{int})+q_{\mathrm{PAR}}(s p)\right]}
$$

The values of RE at different depths were calculated for 38 irradiance profiles in all lakes. At the surface RE $=0$, then it increased with depth to some maximum value, after which it decreased, even reaching zero when $q_{\text {PAR }}$ was very small at depth. In some cases the maximum of RE was 40 to $50 \%$ and mostly it exceeded $15 \%$. The maximum RE was usually observed near the depth of $P_{\max }$. These results agree with those in Arst et al. (2006).

The specific spectral absorption coefficient, $a^{\prime}{ }_{\mathrm{ph}}(\lambda)$, was calculated from Eq. (3) using the intervals $\Delta \lambda$ and averaging the coefficients $A$ and $B$ over these intervals, in place of $\lambda$. After that, $Q_{\mathrm{PAR}}(z)$ was calculated from Eq. (2) using a sum over the PAR range instead of the integral, and, finally, we calculated $Q_{\mathrm{PAR}}^{*}(z)$ by correcting the values of $Q_{\mathrm{PAR}}(z)$ according to Eq. (12) so that:

$$
Q_{\mathrm{PAR}}^{*}(z)=C(z) \sum_{\Delta \lambda} q(\Delta \lambda, z) a_{\mathrm{ph}}^{\prime}(\Delta \lambda) C_{\mathrm{chl}} \Delta \lambda
$$


where the sum was taken over 30 intervals, each of $10 \mathrm{~nm}$ width, in the region from 400 to $700 \mathrm{~nm}$. The correction coefficient $C(z)$ was calculated from Eqs. (13) to (16).

\section{Quantification of the algorithm for quantum yield}

We applied Eq. (22) to all 53 in situ measurements of $P(z)$ in order to determine the values of $M$ and $n$ that gave the best agreement between the measured and calculated profiles of $P(z)$. Both models, spectral and integral, were considered. In the case of the integral model, the first step should be the comparison of photosynthetically absorbed radiation obtained using spectral and integral versions of the model, $Q_{\mathrm{PAR}}^{*}(z, \mathrm{sp})$ and $Q_{\mathrm{PAR}}^{*}(z$, int). It was made for 223 individual pairs of results at the depths from 0.1 to $6 \mathrm{~m}$, while $C_{\mathrm{chl}}$ varied from 4 to $79 \mathrm{mg} \mathrm{m}^{-3}$ (Fig. 7). We left out the cases at the surface, because both $Q_{\mathrm{PAR}}^{*}(z=-0, \mathrm{sp})$ and $Q_{\mathrm{PAR}}^{*}(z=$ -0 ,int) are determined on the basis of the same values, $q(z=-0)$, and differences are very small. The differences between $Q_{\mathrm{PAR}}^{*}(z=-0, \mathrm{sp})$ and $Q_{\mathrm{PAR}}^{*}(z=-0$,int $)$ are notable (Fig. 7); this leads to the conclusion that for the integral model we cannot use in Eq. (22) the same $n$ and $M$ that are suitable for the spectral model. Thus, for the integral model we need new values of $n$ and $M$, which differ from those in the spectral model and are capable of balancing the errors in $Q_{\mathrm{PAR}}^{*}(z)$ of the integral model. It is necessary to explain the mechanism of this 'compensation'. Primary production is calculated as a product of 2 parameters, $Q_{\mathrm{PAR}}^{*}(z)$ and $F_{\mathrm{PAR}}(z)$ (Eq. 11). So, when $Q_{\mathrm{PAR}}^{*}(z)$ has systematic errors for some reason, we have to change $F_{\mathrm{PAR}}(z)$ so that the product $Q_{\mathrm{PAR}}^{*}(z) F_{\mathrm{PAR}}(z)$ has reliable values. For instance, when $Q_{\mathrm{PAR}}^{*}(z)$ is too small, we have to enlarge

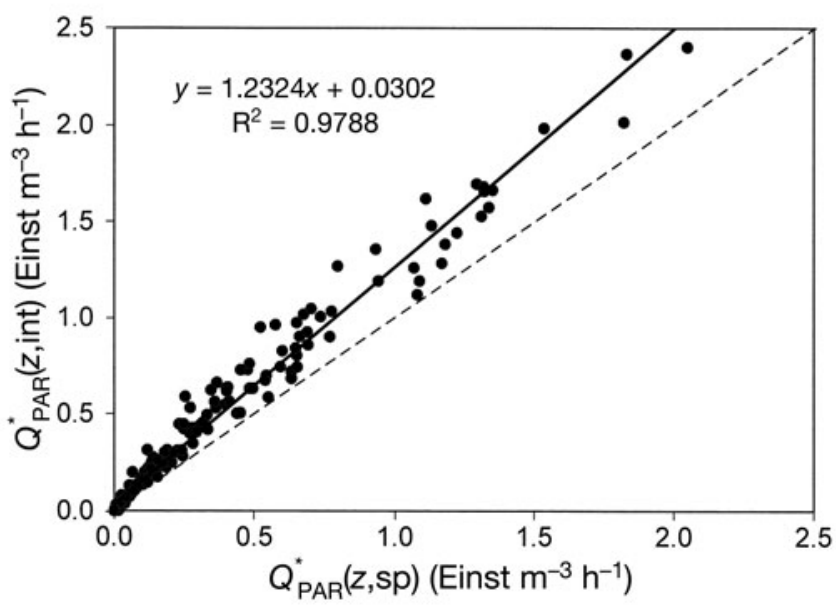

Fig. 7. Comparison of $Q_{\mathrm{PAR}}^{*}(z$, integral $)$ and $Q_{\mathrm{PAR}}^{*}(Z$, spectral $)$ for cases where $C_{\text {chl }}$ varies from 4 to $79 \mathrm{mg} \mathrm{m}^{-3}$ and depths from 0.1 to $6 \mathrm{~m}(\mathrm{~N}=223)$
$F_{\mathrm{PAR}}(z)$ or vice versa. The change of $F_{\mathrm{PAR}}(z)$ is possible when changing the parameters $M$ and $n$ in Eq. (22). Despite the fact that in deeper layers, $P(z)$ is nearly independent of $M$ and $n$, the 'compensation method' markedly improved the results from the integral model.

According to our estimations, a constant value of $n=$ 3 was suitable for the spectral model, and $n=2$, for the integral model. However, the coefficient $M$ varied in each individual case. Use of these 'individual' values of $M$ usually gave very good agreement between measured and calculated profiles of $P(z)$. For practical use of our models, we have to quantify the parameter $M$. We assumed that $M$ is a function of incident irradiance and bio-optical parameters. Tests of different versions (using regression analysis) led us to conclude that our dataset needed to be divided into 3 groups according to chl a content. In 'Group 1', $C_{\text {chl }}$ was from 4 to $35 \mathrm{mg}$ $\mathrm{m}^{-3}$; in 'Group 2', it was from 35 to $100 \mathrm{mg} \mathrm{m}^{-3}$; and in 'Group 3', $C_{\text {chl }}$ was $>100 \mathrm{mg} \mathrm{m}^{-3}$.

In the case of the spectral model, the variations of 'individual' $M$ were from 0.25 to 1.1 (Group 1), from 0.33 to 0.78 (Group 2), and from 0.14 to 0.23 (Group 3). The corresponding variations for the integral model were from 0.45 to 2.2 (Group 1), from 0.65 to 1.5 (Group 2), and from 0.25 to 0.65 (Group 3). Applying the multiple regression analysis, we got suitable equations for $M$ with both models, but only for Groups 1 and 2 . These multiple regression equations and respective statistical parameters are presented in Table 3 . The determination coefficients in Table 3 vary from 0.67 to 0.88 . It can be supposed that in the case of a larger database, $R^{2}$ will be higher and the equations for the parameter $M$ can be, to some extent, different.

In conditions of very high chlorophyll content (Group 3), no good regression between $M$ and the water properties was found; however, a constant value of $M=0.18$ (spectral model) and $M=0.35$ (integral model) gave more or less satisfactory results $(\mathrm{N}=12)$. Remember that the suitability of the spectra of $A$ and $B$ in Eq. (3) for very high $C_{\mathrm{chl}}$ was not proved.

\section{Comparison of measured and calculated primary production}

The vertical profiles of measured, $P$ (meas), and calculated primary production, $P$ (calc), according to the spectral model are compared in Fig. 8a,b. Although some cases exist when $P$ (meas) differed markedly from $P($ calc $)$, most of the measured and calculated vertical profiles of primary production were similar. It was surprising, that even for very high $C_{\mathrm{chl}}$, we found the cases in which the profiles of $P$ (meas) were close to those obtained by the spectral model (Fig. 8b). Because of 
Table 3. Regression formulae for the parameter $M$ (in Eq. 22) for the spectral and integral models of primary production. In these formulae $q_{\mathrm{PAR}}(z=0)$ is in Einst $\mathrm{m}^{-2} \mathrm{~h}^{-1}, C_{\text {chl }}$ in $\mathrm{mg} \mathrm{m}^{-3}$, and $K_{\mathrm{d}, \mathrm{PAR}}$ in $\mathrm{m}^{-1}$. N: number of measurement series

\begin{tabular}{|lccccccc|}
\hline Model & Group & $M$ & $\mathrm{R}^{2}$ & $\mathrm{SE}$ & $\mathrm{p}$ & $\mathrm{N}$ \\
\hline Spectral & 1 & $0.97-0.0036 q_{\mathrm{PAR}}(z=0)-0.067 K_{\mathrm{d}, \mathrm{PAR}}^{2.5}$ & 0.831 & 0.11 & $<0.0001$ & 15 \\
& 2 & $0.80-0.0077 q_{\mathrm{PAR}}(z=0)-0.00066 C_{\mathrm{chl}}$ & 0.713 & 0.07 & $<0.0001$ & 26 \\
& & & & & & \\
Integral & 1 & $1.99+0.028 q_{\mathrm{PAR}}(z=0)-0.154 K_{\mathrm{d}, \mathrm{PAR}}^{2.5}$ & 0.883 & 0.22 & $<0.0001$ & 15 \\
& 2 & $1.58-0.138 q_{\mathrm{PAR}}(z=0)-0.0025 C_{\mathrm{chl}}$ & 0.669 & 0.15 & $<0.0001$ & 26 \\
& & & & & & \\
\hline
\end{tabular}

possible errors in the measurements of the initial data (incident irradiance, $C_{\mathrm{chl}}$, $K_{\mathrm{d}}$ ) and $P$ (meas), it seems that our spectral model performed well in computing primary production in turbid lakes. The main difficulty of using the spectral model is the need for spectral data on $q(\lambda, z=0)$ and $K_{d}(\lambda, z)$. Even so, when no underwater spectrometer is available, the spectral data can be derived from laboratory measurements and a special model for calculation of $K_{\mathrm{d}}(\lambda, z)$.

The regression of $P$ (meas) versus $P$ (calc) for both spectral and integral
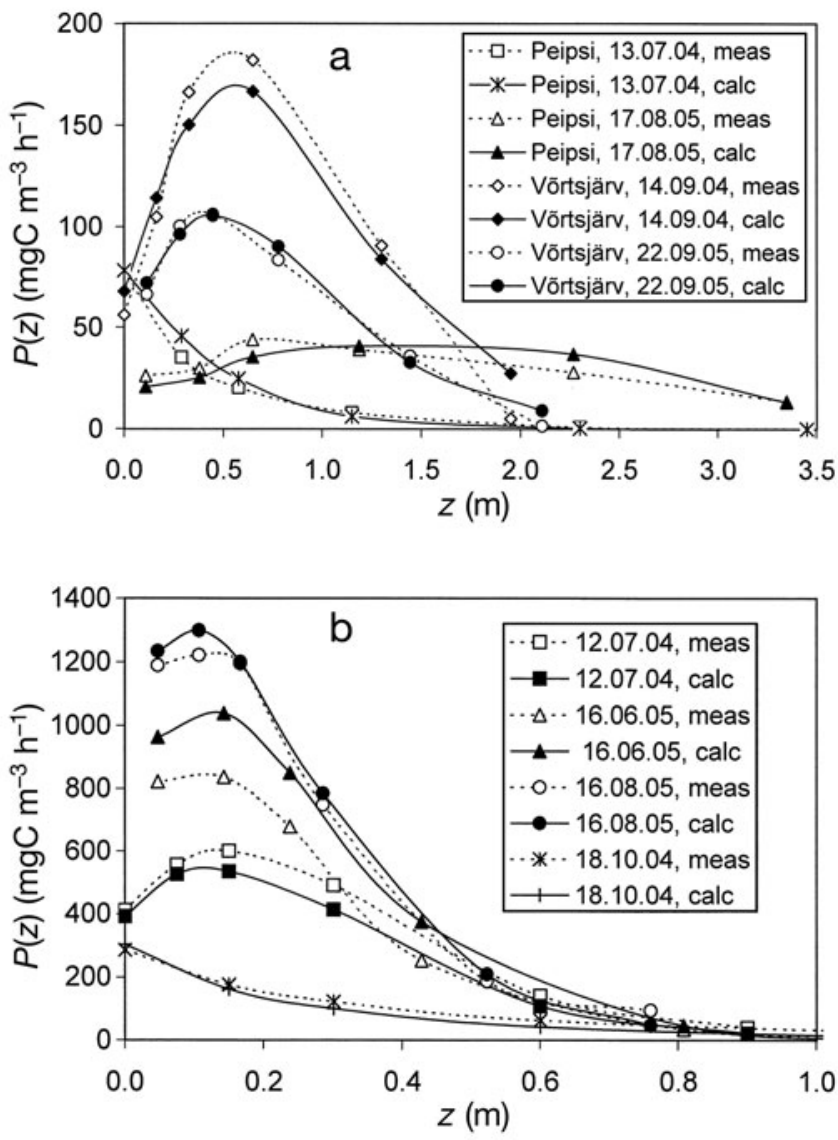

Fig. 8. Comparison of measured and calculated (using spectral model) primary production $P(z)$ : (a) Lake Peipsi-13 July 2004 , where $C_{\mathrm{chl}}=15.5, q_{\mathrm{PAR}}(z=0)=300$, and $K_{\mathrm{d}, \mathrm{PAR}}=2.6$; 17 August 2005, where $C_{\mathrm{chl}}=33, q_{\mathrm{PAR}}(z=0)=1062$, and $K_{\mathrm{d}, \mathrm{PAR}}=1.6 ;$ Lake Võrtsjärv-14 September 2004, where $C_{\mathrm{chl}}$ $=79, q_{\mathrm{PAR}}(z=0)=1300$, and $K_{\mathrm{d}, \mathrm{PAR}}=2.5 ; 22$ September 2005, where $C_{\mathrm{chl}}=67, q_{\mathrm{PAR}}(z=0)=783$, and $K_{\mathrm{d}, \mathrm{PAR}}=2.6$; $(\mathrm{b})$ results obtained for Lake Harku: 12 July 2004, where $C_{\mathrm{chl}}=124$, $q_{\mathrm{PAR}}(z=0)=1308$, and $K_{\mathrm{d}, \mathrm{PAR}}=6.3 ; 16$ June 2005 , where $C_{\mathrm{chl}}=$ $260, q_{\mathrm{PAR}}(z=0)=1160$, and $K_{\mathrm{d}, \mathrm{PAR}}=6.5 ; 16$ August 2005, where $C_{\mathrm{chl}}=333, q_{\mathrm{PAR}}(z=0)=990$, and $K_{\mathrm{d}, \mathrm{PAR}}=7.7 ; 18$ October 2004, where $C_{\mathrm{chl}}=160, q_{\mathrm{PAR}}(z=0)=82$, and $K_{\mathrm{d}, \mathrm{PAR}}=3.4$. The parameters $C_{\mathrm{chl}}, q_{\mathrm{PAR}}(z=0)$, and $K_{\mathrm{d}, \mathrm{PAR}}$ are in $\mathrm{mg} \mathrm{m}^{-3}$, $\mu \mathrm{mol} \mathrm{m} \mathrm{s}^{-2} \mathrm{~s}^{-1}$, and $\mathrm{m}^{-1}$, respectively models (Group 1 and 2 together, $C_{\text {chl }}$ from 4 to $79 \mathrm{mg}$ $\mathrm{m}^{-3}$ ) is illustrated in Fig. 9. We left Group 3 out of our statistical analysis due to the uncertainty of $A$ and $B$ spectra for very high $C_{\text {chl }}$ in Eq. (3) (Bricaud et al. 1995). The results show (Fig. 9) that the spectral model gives the best coincidence between $P$ (meas) versus $P$ (calc), but the integral model (when used with modified parameters $n$ and $M$ from Table 3 ) is not significantly worse. The statistical characteristics of the regression $P$ (meas) versus $P$ (calc) are presented in Table 4 . From these data we can conclude that our spectral model for computation of primary production in turbid lakes is good, but the integral model is also acceptable.

In addition to the vertical profiles of $P(z)$, we estimated the respective integral values, $P_{\text {int, }}$ that were calculated by integration of $P(z)$ over depth. These results can only be considered as approximations for 2 reasons. First, sometimes the first bottle was located 5 to $10 \mathrm{~cm}$ below the surface, not just under it, and, at the maximum depth of measurements, $P(z)$ was not zero, but had some small value. Second, $P_{\text {int }}$ was calculated using the trapezoidal rule, which somewhat underesti-

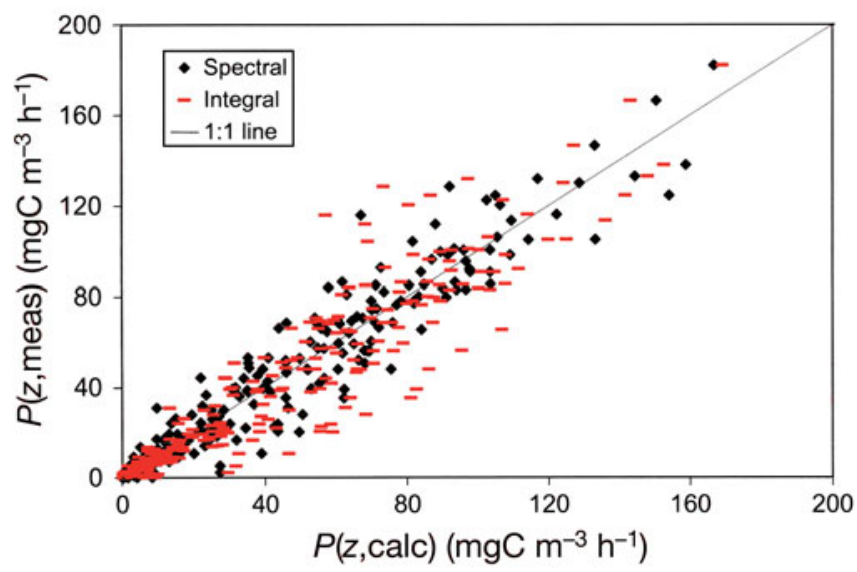

Fig. 9. Comparison of measured and calculated values of primary production, $P(z)$, for spectral and integral models (Groups 1 and 2 together) 
mated $P_{\text {int }}$ in comparison with real values; nevertheless, $P_{\text {int }}$ (meas) and $P_{\text {int }}$ (calc) were calculated similarly and should be comparable.

The regressions of $P_{\text {int }}$ (meas) versus $P_{\text {int }}($ calc) for Groups 1 and 2 together (Fig. 10) showed that, in most cases, the differences between measured and calculated $P_{\text {int }}$ were rather small. The statistical characteristics of these regressions are presented in Table 5.

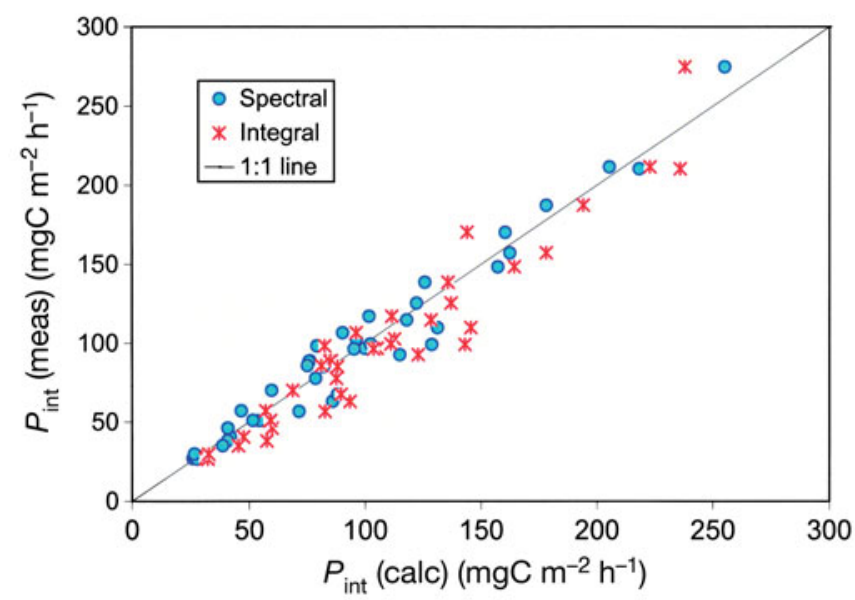

Fig. 10. Comparison of measured and calculated values of integrated primary production, $P_{\text {int }}(z)$, for spectral and integral models (Groups 1 and 2 together, $\mathrm{N}=41$ )

Table 4. Statistical parameters of the regressions $P$ (meas) versus $P$ (calc) for spectral and integral models (Groups 1 and 2 together). AE: mean absolute error; $\mathrm{N}$ : number of points. SE and AE both in $\mathrm{mg} \mathrm{C} \mathrm{m}^{-3} \mathrm{~h}^{-1}$

\begin{tabular}{|lcccccc|}
\hline Model & $\mathrm{R}^{2}$ (adj) & $\mathrm{SE}$ & Regression & $\mathrm{p}$ & $\mathrm{AE}$ & $\mathrm{N}$ \\
\hline Spectral & 0.919 & 11.0 & $y=0.988 x+0.31$ & $<0.00001$ & 0.2 & 241 \\
Integral & 0.856 & 14.7 & $y=0.957 x-0.87$ & $<0.00001$ & 2.8 & 241 \\
\hline
\end{tabular}

Table 5. Statistical parameters of the regressions $P_{\text {int }}$ (meas) versus $P_{\text {int }}$ (calc) for spectral and integral models (Groups 1 and 2 together). AE: mean absolute error; $\mathrm{N}$ : number of points. SE and $\mathrm{AE}$ both in $\mathrm{mg} \mathrm{C} \mathrm{m}^{-2} \mathrm{~h}^{-1}$

\begin{tabular}{|lcclcrr|}
\hline Model & $\mathrm{R}^{2}$ (adj) & $\mathrm{SE}$ & Regression & $\mathrm{p}$ & $\mathrm{AE}$ & $\mathrm{N}$ \\
\hline Spectral & 0.955 & 12.0 & $y=x+1.0$ & $<0.00001$ & 0.2 & 41 \\
Integral & 0.925 & 15.5 & $y=0.989 x-6.8$ & $<0.00001$ & -7.9 & 41 \\
\hline
\end{tabular}

Table 6. Formulas and parameters for calculating the primary production in lakes for spectral and integral models. Note that in the fifth column an equation for determining $a_{\mathrm{ph}}^{\prime}(\lambda)$ is given for the spectral model, but one determining $a_{\mathrm{ph}, \mathrm{PAR}}$ is given for the integral model

\begin{tabular}{|lccccccc|}
\hline Model & $P(z)$ & $Q_{\mathrm{PAR}}(z)$ & $Q_{\mathrm{PAR}}^{*}(z)$ & $a_{\mathrm{ph}}$ & $F_{\mathrm{PAR}}(z)$ & $n$ & $M$ \\
\hline Spectral & Eq. 11 & Eq. 2 & Eq. 12 & Eq. 3 & Eq. 22 & 3 & see Table 3 \\
Integral & Eq. 11 & Eq. 5 & Eq. 12 & Eq. 7 & Eq. 22 & 2 & see Table 3 \\
\hline
\end{tabular}

\section{CONCLUSIONS}

We elaborated 2 versions (spectral and integral) of a to $389 \mathrm{mg} \mathrm{m}^{-3}$ for chl a concentration (separately for 3 groups by $C_{\mathrm{chl}}$ and 0.1 to $3 \mathrm{~m}$ for Secchi depth. ever, due to doubt that the parameter $a_{\mathrm{ph}}^{\prime}(\lambda)$ obtained (according to the data of Bricaud et al. 1995) can be unreliable for very high $C_{\mathrm{chl}}$, we left these cases out of statistical analysis and confined ourselves to the value of $C_{\mathrm{chl}}=79 \mathrm{mg} \mathrm{m}^{-3}$

calculations of primary production, the spectral model needs in situ measured data on chlorophyll content in the water and the spectra (in PAR region) of incident quantum irradiance on the water surface and the corresponding spectra of the diffuse attenuation coefficient of underwater irradiance. The only parameters that are necessary from the literature are the coefficients in the formula for determining the spectra of the absorption coefficient of phytoplankton (e.g. from Bricaud et al. 1995). The integral model also requires the data on chlorophyll, but, from the point of view of radiation characteristics, it is simpler: only in situ measured integral values of incident quantum irradiance in the PAR region and the corresponding diffuse attenuation coefficient $\left(K_{\mathrm{d}, \mathrm{PAR}}\right)$ are necessary. The absorption coefficient of phytoplankton is obtained as an average from its spectral values.

In both models, using regression analysis, a parameterization of Eq. (22) was performed. The results, described in Table 3, are valid at the present stage of the study. It can be supposed that in the case of a larger database, the parameters $M$ and $n$ in Eq. (22) can, to some extent, be different. However, due to good coincidence of measured and cal- 
culated $P(z)$, we can conclude that the present form of Eq. (22) works well.

According to statistical parameters, the preferable model is the spectral model, but the integral model can also be recommended. Both models can be successfully used for estimation of the integrated primary production over the water column. We assume that the models elaborated in the present study can also be used for estimation of primary production profiles in turbid coastal and marginal sea waters.

An important result is the new form of the algorithm for calculation of the vertical profiles of the quantum yield of carbon fixation (Eq. 22). This algorithm was first quantified for the spectral model from in situ data from 3 Estonian lakes. The integral model, in which $Q_{\mathrm{PAR}}^{*}(z)$ was less reliable than that for the spectral model, was improved by changing the coefficients $M$ and/or $n$ in Eq. (22).

Both models allow estimation, not only of the primary production profiles and water-column-integrated production, but also of their daily dynamics and daily and monthly totals. The idea is based on the fact that only incident irradiance varies noticeably, and often irregularly, during a day, but the other initial parameters of the model change slowly over time. Thus, for estimation of the temporal dynamics of primary production in a lake, daily data are needed on incoming PAR irradiance combined with episodic measurements of chl a concentration and the diffuse attenuation coefficient in the water.

Acknowledgements. The authors are indebted to the Estonian Ministry of Education (Target Funding Projects 03962480s03 and 0712699s05) and to the Estonian Science Foundation (Grant 5594) for financial support of this investigation, and to A. Erm, T. Feldmann, M. Hussainov, K. Kangro, E. Lill, and I. Tõnno for their help with field measurements and laboratory analyses.

\section{LITERATURE CITED}

Arst H (2003) Optical properties and remote sensing of multicomponental water bodies. Springer \& Praxis-Publishing, Chichester

Arst H, Mäekivi S, Lukk T, Herlevi A (1997) Calculating irradiance penetration into water bodies from the measured beam attenuation coefficient. Limnol Oceanogr 42:379-385

Arst H, Reinart A, Erm A, Hussainov M (2000) Influence of depth-dependence of the PAR diffuse attenuation coefficient on the computation of downward irradiance in different water bodies. Geophysica 36:129-139

Arst H, Erm A, Reinart A, Sipelgas L, Herlevi A (2002) Calculating irradiance penetration into water bodies from the measured beam attenuation coefficient. II. Application of improved model to different types of lakes. Nord Hydrol 33:207-226

Arst H, Erm A, Kangro K, Nõges T, Nõges P (2006) Comparison of spectral and broad-band models for computing photosynthetically absorbed radiation in turbid waters. Boreal Environ Res 11:55-65
Arst H, Nõges T, Nõges P, Paavel B. (2008) Relations of in situ primary production, underwater irradiance and optically active substances in turbid lakes. Hydrobiologia 599(Spec Issue):169-176

Bannister TT (1974) Production equations in terms of chlorophyll concentration, quantum yield, and upper limit to production. Limnol Oceanogr 19:1-12

Berthon JF, Morel A (1992) Validation of spectral light-photosynthesis model and use of the model in conjunction with remotely sensed pigment observations. Limnol Oceanogr 37:781-796

> Bird RE, Riordan C (1986) Simple solar spectral model for direct and diffuse irradiance on horizontal and tilted planes at the earth's surface for cloudless atmospheres. J Clim Appl Meteorol 25:87-97

> Bricaud A, Babin M, Morel A, Claustre H (1995) Variability in the chlorophyll-specific absorption coefficients of natural phytoplankton: analysis and parametrization. J Geophys Res 100(C7):13321-13332

Dekker AG, Peters SWM (1993) The use of Thematic Mapper for the analysis of eutrophic lakes: a case study in the Netherlands. Int J Remote Sens 14:799-821

Dera J (1992) Marine physics. PWN-Polish Scientific Publishers \& Elsevier, Warsaw \& Amsterdam

Fee EJ (1980) Important factors for estimating annual phytoplankton production in the Experimental Lakes Area. Can J Fish Aquat Sci 37:513-522

Fee EJ, Hecky RF, Welch HA (1987) Phytoplankton photosynthesis parameters in central Canadian lakes. J Plankton Res 9:305-316

Herlevi A (2002) Inherent and apparent optical properties in relation to water quality in Nordic waters. PhD thesis, University of Helsinki. Available in: Report series in geophysics, 45. University of Helsinki

Hilmer T, Bate GC (1989) Filter types, filtration and postfiltration treatment in phytoplankton production studies. J Plankton Res 11:49-63

- Kirk JTO (1981) Estimation of the scattering coefficient of natural waters using underwater irradiance measurements. Aust J Mar Freshwater Res 32:533-539

Kirk JTO (1996) Light and photosynthesis in aquatic ecosystems. Cambridge University Press, Cambridge

> Kyewalyanga M, Platt T, Sathyendranath S (1992) Ocean primary production calculated by spectral and broad-band models. Mar Ecol Prog Ser 85:171-185

Lignell R (1992) Problems in filtration fractionation of ${ }^{14} \mathrm{C}$ primary productivity samples. Limnol Oceanogr 37: 172-178

Lindell T, Pierson D, Premazzi G, Zilioli E (eds) (1999) Manual for monitoring European lakes using remote sensing techniques. Office of Official Publications of the European Communities, Luxembourg, ISBN 92-828-5390-X

Lorenzen CJ (1967) Determination of chlorophyll and phaeopigments: spectrophotometric equations. Limnol Oceanogr 12:343-346

Morel A (1978) Available, usable and stored radiant energy in relation to marine photosynthesis. Deep-Sea Res 25: 673-688

Morel A, Berthon JF (1989) Surface pigments, algal biomass, and potential production of the euphotic layer: relationships reinvestigated in view of remote-sensing applications. Limnol Oceanogr 34:1545-1562

> Morel A, Bricaud A (1981) Theoretical results concerning light absorption in a discrete medium, and application to specific absorption of phytoplankton. Deep-Sea Res 28: 1375-1393

Nielsen GA, Bresta AM (eds) (1984) Guidelines for the mea- 
surement of phytoplankton primary production, 2nd edn, Publ. 1. The Baltic Marine Biologists, Charlottenlund

Niemi M, Kuparinen J, Uusi-Rauva A, Korhonen K (1983) Preparation of algal samples for liquid scintillation counting. Hydrobiologia 106:149-159

Nõges P, Nõges T (1998) Advantages and limitations of optical methods in the estimation of the primary production of lakes. In: Pulkkinen K (ed) Report series in geophysics, 38. Department of Geophysics, University of Helsinki, p 59-67

Platt T (1986) Primary production of the ocean water column as a function of surface light intensity: algorithms for remote sensing. Deep-Sea Res 33:149-163

Platt T, Jassby AD (1976) The relationship between photosynthesis and light for natural assemblages of coastal marine phytoplankton. J Phycol 12:421-430

Platt T, Sathyendranath S (1988) Oceanic primary production: estimation by remote sensing at local and regional scales. Science 241:1613-1620

Platt T, Denman KL, Jassby AD (1977) Modelling the productivity of phytoplankton. In: Goldberg ED, McCave IN, O'Brien JJ, Steele JH (eds) The sea: ideas and observations on progress in the study of the seas, 6. Wiley-Interscience, London, p 807-856

Platt T, Caverhill CM, Sathyendranath S (1991) Basin scale estimates of oceanic primary production by remote sensing: the North Atlantic. J Geophys Res 96:15147-15159

Reinart A (2000) Underwater light field characteristics in different types of Estonian and Finnish lakes. In: Dissertationes Geophysicales Universitatus Tartuensis, 11. PhD, Tartu University Press, Tartu

Sathyendranath S, Platt T (1989) Computation of aquatic primary production: extended formalism to include effect of angular and spectral distribution of light. Limnol Oceanogr 34:188-198

Sathyendranath S, Platt T, Caverhill CM, Warnock RE, Lewis MR (1989) Remote sensing of oceanic primary production: computations using a spectral model. Deep-Sea Res 36: 431-453

Schindler DW (1978) Factors regulating phytoplankton production and standing crop in the world's freshwaters. Limnol Oceanogr 23:478-486

Schofield O, Bidigare RR, Prézelin BB (1990) Spectral photosynthesis, quantum yield and blue-green light enchance-

Editorial responsibility: Jonathan Cole,

Millbrook, New York, USA ment of productivity rates in the diatom Chaetoceros gracile and the prymnesiophyte Emiliana huxleyi. Mar Ecol Prog Ser 64:175-186

Semovski SV, Wozniak B, Hapter R, Staskiewitz A (1996) Gulf of Gdansk spring bloom physical, bio-optical, biological modelling and contact data assimilation. J Mar Syst 7: 145-159

Siegel DA, Westberry TK, O'Brien MC, Nelson NB and others (2001) Bio-optical modeling of primary production on regional scales: the Bermuda BioOptics project. Deep-Sea Res 48:1865-1896

Smith RC, Prézelin BB, Bidigare RR, Baker KS (1989) Biooptical modeling of photosynthetic production in coastal waters. Limnol Oceanogr 34:1524-1544

Smith RC, Baker KS, Byers ML, Stammerjohn SE (1998) Primary productivity of the Palmer Long Term Ecological Research Area and the Southern Ocean. J Mar Syst 17: $245-259$

Sosik HM (1996) Bio-optical modelling of primary production: consequences of variability in quantum yield and specific absorption. Mar Ecol Prog Ser 143:225-238

Steeman-Nielsen E (1952) The use of radioactive carbon $\left({ }^{14} \mathrm{C}\right)$ for measuring primary production in the sea. J Cons Int Explor Mer 18:117-140

Talling JF, Wood RB, Prosser MV, Baxter RM (1973) The upper limit of photosynthetic productivity by phytoplankton: evidence from Ethiopian soda lakes. Freshw Biol 3: $53-76$

Tilzer MM (1984) The quantum yield as a fundamental parameter controlling vertical photosynthetic profiles of phytoplankton in Lake Constance. Arch Hydrobiol Suppl 69: $169-198$

Tilzer MM (1989) The productivity of phytoplankton and its control by resource availability. In: Kumar HD (ed) Phycotalk. Bavaras Hindi University, Varanasi, p 1-40

Woznyak B, Dera J, Koblenz-Mishke OJ (1992) Modelling the relationship between primary production, optical properties and nutrients in the sea. In: Gilbert ED (ed) Ocean Optics XI, Proc SPIE 1750:246-275

Woznyak B, Dera J, Semovski S, Hapter R, Ostrowska M, Kaczmarek S (1995) Algorithm for estimating primary production in the Baltic by remote sensing. Stud Mater Oceanol 68:91-123

Submitted: September 24, 2007; Accepted: May 13, 2008 Proofs received from author(s): June 20, 2008 